Derecho y Realidad

Núm. 24 • Il semestre de 2014

Facultad de Derecho y Ciencias Sociales, UPTC

ISSN: 1692-3936

\title{
La reelección presidencial en Latinoamérica: un avance en el caudillismo $y$ un retroceso en la democracia
}

\author{
The presidential re-election in Latin America: a \\ breakthrough into warlordism and a setback for \\ democracy
}

Carlos Alfonso Cárdenas Hernández*

\section{Resumen}

El caudillismo es el régimen político que caracteriza la cultura política latinoamericana, y la reelección es un instrumento utilizado por los defensores de este sistema, para mantenerse en el poder en detrimento de la democracia republicana. De ahí que, para garantizar el ejercicio de esta democracia, se deba limitar el ejercicio del poder presidencial a un periodo razonable, sin posibilidad de reelección, a fin de fortalecer los partidos políticos que dinamizan la democracia.

\section{Palabras clave}

Presidencialismo, reelección, democracia, caudillismo.

\footnotetext{
* Abogado egresado de la Universidad Pedagógica y Tecnológica de Colombia. Especializado en Derecho Constitucional de la Universidad Nacional en convenio con la Universidad Pedagógica y Tecnológica de Colombia. Docente investigador de la Universidad Pedagógica y Tecnológica de Colombia. Con maestría en Derecho Público de la Universidad Santo Tomás de Bogotá en convenio con la Universidad de Konstanz de Alemania. Integrante del grupo de investigación Red Humana.
} 
Derecho y Realidad

\begin{abstract}
Warlordism is the political regime that characterizes the political culture in Latin American, and the re-election is a tool used by the supporters of this system to stay in power at the expense of republican democracy. Hence, to ensure the exercise of this democracy, the exercise of presidential power must be limited to a reasonable period, without re-election, to strengthen political parties, that invigorates democracy.
\end{abstract}

\title{
Keywords
}

Presidential, re-election, democracy, warlordism. 


\section{Introducción}

Esta ponencia se inicia con la formulación del siguiente interrogante: ¿La reelección presidencial en Latinoamérica favorece la democracia mayoritaria y caudillista en detrimento de la democracia republicana? Es preciso tratar este tema, ya que en los últimos años se han agudizado las reformas constitucionales en Latinoamérica que propugnan el mantenimiento en el poder de sus mandatarios en detrimento de la democracia. Para responder este interrogante se divide este artículo en los siguientes capítulos:

1. La democracia mayoritaria y caudillista en Latinoamérica.

2. La alternancia del poder como una garantía de la democracia republicana.

3. Conclusiones.

Estos temas fueron desarrollados a través de una exploración teórica que nos llevaron a describir el fenómeno para dar una propuesta a fin de fortalecer la democracia en América Latina como una alternativa a la reelección presidencial.

Por tal motivo, este trabajo es empírico-analítico, ya que pretende, a través de hechos puntuales, analizar el problema planteado para dar una propuesta a manera de conclusión.

\section{La democracia mayoritaria y caudillista en Latinoamérica}

En este capítulo pretendemos establecer como la democracia mayoritaria y caudillista es el régimen político imperante en Latinoamérica y como la reelección es la forma legítima para mantenerlo.

Latinoamérica, desde los albores de su independencia de la metrópoli española, ha tratado de consolidar su democracia bajo los principios de las democracias liberales de Europa y Estados Unidos, regentadas por la libertad, la igualdad y la voluntad general. Sin embargo, Latinoamérica ha adoptado su propio régimen democrático basado en el caudillismo, que acude al sentimiento mayoritario para establecer su propia ideología particular en la búsqueda del interés general y el bien común.

Este fenómeno empezó en Latinoamérica en el siglo XIX con los caudillos locales y provinciales, que son la base del poder del caudillo nacional, dentro de una organización piramidal con sus subordinados, mediante una relación de patrón a cliente. El patrón protege y recompensa al cliente de acuerdo con sus labores y a costa de una total adhesión (Rebon, 2007). 
Tanto en Colombia como en varios países de Latinoamérica, el fenómeno del caudillismo está relacionado con el régimen presidencial, y unidos forman el concepto del poder presidencialista que aún perdura y se ha visto reflejado en las reformas constitucionales que buscan mantener al presidente en el poder por más de un periodo presidencial.

Esta tendencia se ve establecida en el hecho de que en los países latinoamericanos el régimen homogéneo democrático es el presidencial, que tiene como característica el poder ejecutivo y la jefatura del Estado en cabeza de una sola persona, lo cual, unido al caudillismo como expresión política dentro de la dinámica democrática latinoamericana, ha desfigurado la concepción inicial del poder presidencial estadunidense basado en los controles mutuos para limitar el poder presidencial (respetando de manera irrestricta la independencia y autonomía de los poderes) de aquel que aspira perpetuarse en el poder acudiendo a la popularidad y a la mayorías, mediante una actitud autoritaria.

El caudillismo, como un rasgo propio del sistema político latinoamericano, ha manifestado las siguientes características:

1. Los caudillos vienen generalmente del cuerpo militar o son civiles que descansan principalmente en los militares para su apoyo y sostenimiento. Y a su vez, su permanencia en el poder depende en buena medida del control que ejercen sobre la institución armada.(Castro, 2007, p. 16)

2. El liderazgo del caudillo se caracteriza por un fuerte estilo personalista y de su manera correspondiente de relacionarse con la ciudadanía. La palabra es el vehículo especíûco del carisma. Es el hombre providencial que resolverá, de una buena vez y para siempre, los problemas del pueblo. Habla con su público de manera constante, atiza sus pasiones, le "alumbra el camino", y lo hace sin limitaciones ni intermediarios. Se erige en intérprete de los intereses populares, y pretende encarnar el proverbio latino vox populi, vox dei. El caudillo gobierna de una manera paternalista y altamente centralizada. (Castro, 2007, p. 16)

3. En un sentido político, usaríamos "caudillaje" para aplicarlo a ese régimen que consiste en la personiûcación o encarnación de la autoridad, donde el que gobierna actúa con una ascendencia carismática moral extraordinaria sobre su gente: les aconseja, guía, conduce paternalmente. El caudillaje aparece como una institución social plena de contenido ético (control político y militar, la auténtica totalidad del poder, el liderazgo psíquico de los gobernados, el magnetismo moral de la personalidad del líder) que lo hace más adecuado para aquellos Estados cuya vida política es determinada por la integración de valores tradicionales individuales y colectivos. (Castro, 2007, p. 16) 
4. Los caudillos tienden a permanecer en su puesto por un periodo extenso de tiempo (continuismo), en tanto que se tiende a despreciar el orden legal y mina, domina, domestica o cancela las instituciones de la democracia liberal, construye las condiciones necesarias para su perpetuación en el poder. La experiencia histórica señala que ningún caudillo permanece poco tiempo en su puesto, y que su salida siempre es forzosa. Los caudillos generalmente gobiernan de una manera autocrática, que con frecuencia implica la supresión de la oposición, la creación de partidos y movimientos oficiales y la supresión de otros. Aunque no siempre lo hace, o no siempre tiene éxito en su intento, el caudillo favorece la formación de partidos únicos o de movimientos que le respaldan y que se proyectan hacia el futuro. (Castro, 2007, p. 16)

5. Los caudillos pueden gobernar de una manera autoritaria, que es con frecuencia un reûejo de las propias normas y expectativas generales de su propia sociedad, ellos pueden ser no completamente totalitarios. Hay límites más allá de los cuales el líder no iría. Gobernar de una manera tiránica viola el contrato social informal pero plenamente comprendido o "reglas del juego" que gobiernan las relaciones del caudillo con la sociedad política. A pesar de su tendencia a someter a las instituciones y movimientos que le sean contrarios, el caudillo no está en la capacidad de someter a una sociedad en su totalidad, sino que focaliza sus políticas represivas en sectores especíûcos. (Castro, 2007, p. 17)

6. A esta lista habría que agregar que el caudillo tiene la necesidad funcional de atacar a los "enemigos del pueblo", tanto internos como externos. Moviliza a grupos sociales bajo la bandera de la defensa nacional de los ataques del adversario $\mathrm{y}$, pudiendo ser reales, tienden a llevarse al punto de enemigos mortales y chivos expiatorios de los fracasos, originándose estados de exaltación y paranoia colectiva. (Castro, 2007, p. 18)

Ante estas características, encontramos que el caudillismo es un modelo democrático propio de Latinoamérica, pues en él se expresa la realidad política de nuestras instituciones, las cuales carecen de estabilidad política, lo que favorece que las políticas autoritarias dominen la sociedad latinoamericana, que considera legítimas las estructuras autoritarias y dignas de ser aceptadas o apoyadas, ya que el ejercicio de un gobierno fuerte acaba el faccionalismo, centraliza el poder e impone la paz en el territorio.

Las reformas constitucionales que ha habido en la última década en Latinoamérica han hecho que los mandatarios, con una aceptación abrumadora de la población, pretendieran mantenerse en el poder. A continuación indicamos algunos ejemplos: 


\subsection{Consecutiva e indefinida}

Nicaragua se convirtió en el segundo país, después de Venezuela, en avalar la reelección presidencial indefinida, luego de que el Congreso derogó, con una enmienda constitucional, la prohibición a la reelección presidencial sucesiva y alterna en más de una oportunidad, que regía desde 1996.

La reforma -impulsada por la izquierda sandinista en el poder- quedará firme cuando sea ratificada por el Congreso en el año 2014.(Redacción internacional, 2014)

En Venezuela, la reelección indefinida fue aprobada en el año 2009 con un referéndum sobre una enmienda constitucional, impulsada por el ahora fallecido presidente Hugo Chávez (1999-2013). El mandato presidencial es de seis años.

Antes de la llegada de Chávez al poder, Venezuela permitía la reelección, pero 10 años después a la culminación del mandato presidencial. (Redacción internacional, 2014)

\subsection{Consecutiva por una vez}

En Argentina se consagró con la reforma constitucional del año 1994, bajo la presidencia de Carlos Menem, el primero en ser reelecto en el año 1995; los mandatos son de cuatro años con la posibilidad de una sola reelección. (Redacción internacional, 2014)

En Brasil entró en vigor en el año 1998, en virtud de una enmienda constitucional aprobada para permitir un segundo mandato inmediato al socialdemócrata Fernando Henrique Cardoso (1995-2002). El presidente brasileño puede concurrir a un máximo de dos mandatos consecutivos. (Redacción internacional, 2014)

En Bolivia, la Constitución aprobada en referéndum en el año 2009 introdujo esta figura. Antes se permitía una sola reelección tras un receso presidencial de 5 años. (Redacción internacional, 2014)

Colombia adoptó la reelección inmediata en el año 2005, bajo el régimen de Álvaro Uribe (2002-2010). El período presidencial es de cuatro años. (Redacción internacional, 2014)

En Ecuador, la Constitución del año 2008, impulsada por Rafael Correa, establece la reelección inmediata por una sola vez por un período de cuatro años. Antes, la reelección en Ecuador era autorizada en períodos no consecutivos y de manera indefinida. (Redacción internacional, 2014) 
Lo común a todas estas reformas constitucionales se ve reflejado en la necesidad de dar continuidad (sin importar la orientación ideológica) a un proyecto político mediante una reforma constitucional, ya que lo que los une es la concreción del caudillismo como régimen político auténtico latinoamericano, que a través de la reelección en sus diferentes matices, pretende en menor o mayor medida rendir culto a la personalidad.

Lo anterior se explica porque la izquierda -que antes luchó contra la reelecciónhoy aplaude o se queda en silencio sobre la reelección presidencial, y la derecha -que la apoyó y se benefició con ella- quiere convertirse ahora en la abanderada del antirreeleccionismo. Lo que no solo es manifestación de cierto daltonismo político, sino pragmatismo oportunista. (Tuesta, 2013)

Es, por lo tanto, a través de esta manera como se legitiman las medidas autoritarias tanto de izquierda como de derecha, puesto que en América Latina existe una notoria ausencia de controles. La ausencia de control suficiente se da dentro de una muy débil trama institucional, con una marcada pervivencia del personalismo político y una cultura fuertemente asociada al caudillismo, el paternalismo y el populismo. (Serrafero, 2011, p. 228)

Esto se ha visto reflejado en la última década en Latinoamérica, pues en los regímenes presidencialistas la reelección presidencial del ejecutivo es la base de la supervivencia política del líder y cuando las reglas limitan esta posibilidad y los líderes encuentran las condiciones para hacerlo, buscarán en términos estratégicos cambiar las reglas del juego y sobrevivir políticamente manteniéndose en el cargo. (Sánchez, 2011, p. 8)

Por eso, los líderes ejecutivos -al estar afectados por el constreñimiento que imponen las normas constitucionales para volver a postularse una vez se haya cumplido el período de su gobierno- buscan, antes de abandonar el mandato, hacer un cálculo estratégico para intentar vencer esos obstáculos constitucionales que los desplazarían del poder. (Sánchez, 2011, p. 8)

En último término podemos indicar que la reelección presidencial es la expresión del caudillismo latinoamericano, que aprovecha la cultura política de esta parte del mundo, que desde antaño está educada en mantener los regímenes autoritarios basados en líderes carismáticos, los cuales están por encima de los partidos y los usan para establecer una plataforma electoral para la consecución de sus propósitos, que es favorecido por un sistema de partidos débil que permite que se hable de "partidos presidencializados que surgen de un agente individual responsable de la "salud de la nación", al que se le visualiza como predispuesto a ocuparse de la provisión de bienes públicos”(Sánchez, 2011, p. 13). 
Por tal motivo, se considera la reelección la forma de poder juzgar al mandatario presidencial de forma directa mediante el voto premio/castigo. Por eso, en "los partidos presidencializados los presidentes no tienen incentivos para rendir cuentas ante sus propios colegas del partido. Dado que pueden hacerlo directamente a sus electores" (Sánchez, 2011, p. 13). Siendo esta la razón por la cual las reformas de la última década a la reelección presidencial en los países latinoamericanos fueron para mantener a aquellos presidentes que tenían bastante popularidad.

Por ejemplo, para la reelección de Álvaro Uribe Vélez en Colombia, él tenía un 69 $\%$ de popularidad (año 2004), para la de Rafael Correa en Ecuador, él tenía un 50,2 \% (año 2008), para la de Hugo Chávez en Venezuela, un 43,4 \% (año 2009) y para la de Evo Morales de Bolivia, un 36,1 \% (año 2009), (Barómetro de las Américas del Proyecto de Opinión Pública -LAPOP-, s.f.)

Lo anterior demuestra que el caudillismo, unido a un margen de popularidad, incentiva los anhelos reeleccionistas de los mandatarios, y cuando uno de ellos lo consigue, se genera un efecto dominó en la región. Situación que hace entrever una nueva maniobra que afecta la democracia republicana de estas naciones, al no materializar el control del poder a través de instituciones sólidas que permitan la alternancia del poder.

\section{La alternancia del poder como una garantía de la democracia republicana}

En este capítulo pretendemos establecer que la mejor forma de garantizar la democracia republicana es la alternancia del poder, pero si persiste la reelección, que esta sea la alterna limitada, y que la mejor forma de mantener la democracia en la región es a través de un periodo presidencial razonable para garantizar los derechos a la igualdad de oportunidades a fin de acceder al poder a través de la alternatividad partidista.

La democracia republicana plantea que un régimen político para que sea democrático debe cumplir con los siguientes requisitos:

1. Mecanismo efectivo de división de poderes.

2. Rotación en los cargos públicos.

3. Publicidad y transparencia de los actos de gobierno.

4. Responsabilidad política de los gobernantes.

5. El respeto a la ley es el requisito básico de convivencia social y de progreso.

6. La existencia y vigencia de libertades y derechos individuales.

7. El gobierno de la mayoría y el respeto de las minorías.

8. Reglas y procesos claros y transparentes que definan la participación de los ciudadanos en la función pública y administrativa. 
Ante estos requisitos, los países latinoamericanos han considerado que al abogar por la reelección presidencial no se afecta la democracia republicana, y como ejemplo mencionan la nación estadunidense sin tener en cuenta que este Estado tiene una cultura política diferente, ya que allí la reelección está enmarcada en un sistema institucional de frenos y contrapesos, en el cual se le da un mayor peso al Senado y un papel más activo a la Corte, lo que unido a su estructura federal compensa el probable intento de acumulación excesiva de poder del presidente, quien debe gobernar con la existencia de subgobiernos dentro del aparato ejecutivo, el bipartidismo y la indisciplina partidaria. (Serrafero, 2011, p. 3)

En cambio, en América Latina, el tener un sistema institucional no adecuado la ha llevado a un presidencialismo fuerte o hipertrófico, donde la división de poderes fue conculcada recurrentemente y la libertad fue más violada que practicada. Emergió el predominio del Ejecutivo, y la división de poderes concluyó, numerosas veces, en la subordinación del Congreso y en la franca dependencia del poder judicial a la agencia ejecutiva. Otras situaciones no fueron menos censurables. A veces se llegó al conflicto institucional irreductible -entre Ejecutivo y el Congreso o el poder judicial- donde el presidente tenía más posibilidades de triunfo y, también hubo -aunque menos- situaciones de aislamiento interorgánico. (Serrafero, 2011, p. 3)

Sin embargo, los países latinoamericanos que están dentro de un régimen democrático no han dejado de lado el paradigma de que las normas jurídicas deben ser acatadas por todos los ciudadanos, especialmente por los que ejercen funciones de dirección y administración en el Estado.

Por lo tanto, a pesar de que el caudillismo está aún imperante bajo el nuevo ropaje de la democracia legitimada por el carisma del gobernante, que, a diferencia de las dictaduras militares que vigorizaban el caudillismo por la fuerza, hace que se promuevan reformas constitucionales para mantenerse en el poder.

A pesar de tener un ropaje legal, en la práctica se ha descubierto que de todas las reelecciones aprobadas, la más perjudicial ha sido la reelección inmediata, como en Colombia, Bolivia, Ecuador, Brasil y Argentina, y la indefinida o ilimitada, como en Venezuela y Nicaragua, puesto que en esos países los controles son débiles y la injerencia del ejecutivo es evidente.

Carlos Ariel Sánchez Torres, para el caso de Colombia, indica que frente a la reelección inmediata después que el 7 de agosto del año 2006 de Álvaro Uribe como presidente de Colombia para el período 2006-2010, se inicia una serie de cambios tanto estructurales como coyunturales. Porque Uribe quedó con un poder muy concentrado al poder de influir en siete altos cargos, de otras instituciones diferentes de la rama ejecutiva. Primero, el Banco de la República, ya que en el 
año 2009 Uribe nombró dos de los miembros de la junta del banco, completando, cinco miembros nombrados por él, más el ministro de Hacienda, con lo cual nombró a seis de los miembros de la junta directiva del Banco de la República, que dirige la política económica del país. (Sánchez, 2004)

Así mismo influyó en los nombramientos en la Corte Constitucional, que hace parte de la rama judicial, pues hasta el año 2009 se terminó el periodo de seis de los magistrados de la Corte, y el Congreso, que era mayoritariamente uribista, escogió magistrados de ese talante. (Sánchez, 2004)

El Consejo de la Judicatura también fue influenciado por las decisiones de Uribe, ya que a todos sus miembros se les acabó su periodo en el año 2008 y las elecciones de los otros magistrados fueron ternas enviadas por el Gobierno, es decir, Uribe. (Sánchez, 2004)

La Contraloría General la definió el Congreso, es decir, Uribe, ya que la mayoría era uribista y el control fiscal fue hecho por un uribista. El procurador General, el defensor del Pueblo y el fiscal General también fueron elegidos durante el período de Uribe 2006-2010. (Sánchez, 2004, pág. 11).

No obstante lo anterior, frente a la aprobación de la reelección del año 2006, se presentaron varias denuncias de favorecimientos para su aprobación en el Congreso, lo que dilucida lo frágil de la democracia latinoamericana y lo antidemocrático de esta figura.

En el caso de Venezuela nos encontramos con la reelección indefinida, pues el presidente Hugo Chávez, que gobernó este país desde el año 1999, buscó una nueva reelección para ejercer la primera magistratura hasta el año 2019 o 2021, inclusive. (Márquez, 2008). Con el inconveniente de que allí se pretendió con esta figura repeler -según él- el "contraataque revolucionario" de los opositores que consiguieron hacerse con gobernaciones en cinco de los 23 estados del país y la emblemática alcaldía mayor de Caracas. Chávez dijo, entonces, que tomó la decisión cuando le llegaron informes de que personas afectas a gobernadores de oposición, elegidos en algunos estados, "han atacado para desalojar a los médicos y médicas cubanas de las residencias que ellos ocupan, así como sedes educativas, mercados de alimentos y otras obras sociales". (Márquez, 2008)

Por eso, él consideraba que la reelección era la forma de contrarrestar las posibles represalias a programas sociales que su administración ha impulsado, como la atención primaria de salud a cargo de profesionales cedidos por el gobierno de Cuba, las misiones de alfabetización y educación de adultos y los servicios de venta de alimentos a precios subsidiados para los más pobres.(Márquez, 2008) 
Chávez fue elegido en el año 1998 para gobernar durante el quinquenio 19992004, pero una nueva Constitución le permitió postularse en el año 2000 y en el año 2006. Según la Constitución, el presidente solo podía aspirar una vez a la reelección, por lo que debería entregar su cargo en enero del año 2013, pero el mandatario apuntó que "el chavismo sin Chávez no existe", lo que justifica su postulación para sostener su proyecto político que denomina revolución bolivariana y socialismo del siglo XXI. (Márquez, 2008)

Ya con la enmienda aprobada en el año 2009, Hugo Chávez podría perpetuarse en el poder gracias a la aceptación de la reelección indefinida con un amplio margen que le permitió en el año 2012 volver a ser candidato por otros seis años. Con una victoria del sí a la reforma constitucional con el 54, 36 \% de los votos, mientras que el no, que proponía la oposición, obtuvo un porcentaje de 45,63\%. Así que con esta victoria Chávez pudo proclamar que construiría la patria socialista (Ibarz, 2009).

Hugo Chávez fue reelecto en octubre del año 2012, pero muere en el año 2013 y queda como su sucesor Nicolás Maduro, quien ha sido el reflejo de lo antidemocrático de la reelección presidencial, ya que él, siendo el vicepresidente, con una hábil maniobra política, encarnó la imagen de Hugo Chávez. Se dio así continuidad a un mandato, en el que las acusaciones de fraude no se hicieron esperar.

Con estos dos ejemplos podemos decir que la reelección más nefasta para una democracia es la ilimitada o indefinida, pues en ella se puede evidenciar que en aquellos países donde se quiere establecer un nuevo régimen revolucionario, no acudiendo a las armas, sino a las herramientas democráticas, es a través de esta institución como sus aspiraciones pueden concretarse a largo plazo muy al estilo del nacional socialismo.

Podemos seguir con otros ejemplos en los que se reiteran las críticas al nuevo sistema, debido a la vulneración del principio de igualdad electoral y alternancia como soportes de la democracia republicana. Efectivamente, los hechos así lo demuestran, pues desde el año 2009 hasta hoy han tenido lugar comicios presidenciales en 17 países latinoamericanos, y en todos los que existía la figura de la reelección continua, los presidentes la obtuvieron puesto que contaban a su favor la facilidad de tener a la mano los recursos e instituciones del Estado para competir.(Rojas, 2009)

Ante la imposibilidad de tener un régimen parlamentario por la tradición política latinoamericana, la solución frente a la evidente desventaja entre el presidente candidato y los demás candidatos, es que se emitan leyes de garantías electorales, como sucedió en Colombia, para preservar la igualdad en la contienda electoral. 
A pesar de estos controles legales, siempre dará como resultado la victoria del presidente en ejercicio, por tal motivo proponemos dos posibilidades para frenar el auge reeleccionista automático o indefinido en la región latinoamericana, que perpetúa el régimen caudillista que tanto daño ha hecho a la democracia republicana:

1. Que se establezca un periodo largo para el ejercicio del cargo de presidente, por ejemplo, ocho años sin reelección.

2. Que se determine la reelección alterna por una sola vez.

Descartamos la reelección alterna de manera indefinida, ya que no daría posibilidad a la renovación partidista y es necesario que haya nuevas ideas y dirigentes en los partidos.

Nos inclinamos más por un periodo largo de ocho años sin reelección, por el fortalecimiento de los partidos políticos como soporte de la democracia y por el cambio de los partidos presidencializados por unos que sean de influencia parlamentaria $^{1}$, para que se puedan garantizar la democracia participativa y representativa sin coacciones basadas en la obtención de los favores del jefe, sino con la idea de preservar un proyecto de sociedad, Estado y nación, sin importar la persona que lo dirija. Además se requiere el establecimiento de controles en las demás instituciones del Estado para generar un contrapeso al poder presidencial, como por ejemplo la no coincidencia en los periodos de gobierno y la no posibilidad de nombrar la terna o un integrante de ella, cuando se eligen funcionarios de elección que hacen parte de los organismos de control.

Un periodo de ocho achos permitiría que el presidente surgido de las bases del partido desarrolle, junto a su grupo parlamentario, la propuesta que fue elegida por la ciudadanía, y posibilitaría, en caso de ser contrario, que pueda ser controlado por su partido si se quiere mantener el proyecto partidista en el poder. Si el proyecto no ha sido cumplido, el partido opositor puede acceder al poder y tener la oportunidad de plantear su propuesta y ejecutarla, ya que el poder debe sustentarse en las bases y no en el caudillo manipulando a las bases.

En definitiva es importante garantizar la alternancia del poder y la forma más adecuada es dar un tiempo razonable al presidente para que guíe el proyecto del partido y dé la posibilidad de renovación en la dirigencia, a fin de oxigenar la colectividad con un nuevo periodo, si la ciudadanía así lo decide. Máxime si uno

\footnotetext{
Al respecto, un partido parlamentarizado fusiona sus funciones ejecutivas y legislativas, seleccionando a su líder y haciéndole responsable a través de un proceso interno de selección. Es decir, el partido es el principal y el ejecutivo es el agente, responsable ante el principal.
} 
de los postulados de la democracia es la igualdad de oportunidades y una de esas oportunidades es tener la posibilidad de acceder al poder.

\section{Conclusiones}

Ante los puntos tratados hemos llegado a las siguientes conclusiones:

1. El caudillismo es el régimen político que ha caracterizado la cultura política latinoamericana, por tal razón ha sido discutido y desarrollado el tema de la reelección, pues esta siempre enmascara regímenes autoritarios tanto de derecha como de izquierda.

2. La manera como se pueden garantizar los principios de alternancia e igualdad democrática es mediante la determinación de un periodo razonable sin reelección, pues de esta manera se lograrían fortalecer los partidos políticos que son el soporte de la democracia, para guiar al ciudadano a valorar los proyectos partidistas y no el carisma de los dirigentes.

3. La reelección más nefasta para una democracia es la ilimitada o indefinida, pues en ella se puede evidenciar que en aquellos países donde se quiere establecer un nuevo régimen revolucionario, sin acudir a las armas, sino a las herramientas democráticas, es a través de esta institución como sus aspiraciones pueden concretarse a largo plazo muy al estilo del nacional socialismo.

\section{Referencias}

Barómetro de las Américas del Proyecto de Opinión Pública -LAPOP-. (s.f.). Base de datos. Recuperado de www.lapopSurveys.org

Castro, P. (2007). Caudillismo en América Latina, ayer y hoy. Cultura y Política, Primavera, (27), 9-29.

Ibarz, J. (2009, 16 de febrero). Chávez gana el referendum que le permite reelección indefinida. Lavanguardia.com. Recuperado de http://www.lavanguardia.com/ internacional/20090216/53640949713/chavez-gana-el-referendum-que-lepermite-la-reeleccion-indefinida.html

Márquez, H. (2008, 1 de dic.). Venezuela retoma debate sobre reelección presidencial. Ipsnoticias.net. Recuperado de http://www.ipsnoticias.net/2008/ 12/venezuela-retorna-debate-sobre-reeleccion-presidencial/

Rebon, S. (2007, 30 de mayo). El fenómeno del caudillismo en Latinoamérica en el siglo XIX. Academia.edu. Recuperado de http://www.academia.edu/ 4289066/El_fenomeno_del_Caudillismo_en_Latinoamerica_en_el_siglo_XIX 
Redacción internacional. (2014, 14 de enero). La reelección presidencial toma auge en Latinoamérica. Lahora.com. Recuperado de http://www.lahora.com. ec/index.php/noticias/show/1101619346/-1La_reelecci\% C3\% B3n presidencial_toma_auge_en_Latinoam\%C3\%A9rica.html\#.Uthz3fTuJqU

Rojas, A. (2009, 9 de junio). Reelección en América Latina. Eldiarioexterior.com. Recuperado de http://www.eldiarioexterior.com/reeleccion-en-america-latinano-42312.htm

Sánchez, C. A. (2004, 4 de agosto). Revista Civilizar, (11). Recuperado de http:/ /www.usergioarboleda.edu.co/civilizar/revista11/impacto_reeleccion_ presidencial.pdf

Sanchez, I. T. (2011, 21 de enero). Campus. usal.es. Recuperado de http://campus. usal.es/ acpa/sites/default/files/paper_seminario_ilka_treminio.pdf

Serrafero, M. D. (2011, mayo). Reelección presidencial indefinida en América Latina. Revista de Instituciones, Ideas y Mercados(54), 225-259.

Tuesta, F. (2013, 2 de enero). La reelección presidencial en América Latina. Nueva Mayoría. com. Recuperado http://www.nuevamayoria.com/ index.php?option $=$ com_content\&task $=$ view $\&$ id $=3769 \&$ Itemid $=1$ 